\title{
A Land Resources Planning Toolbox to Promote Sustainable Land Management
}

\author{
Feras Ziadat ${ }^{1}$, Eddy De Pauw ${ }^{1}$, Freddy Nachtergaele ${ }^{1} \&$ Theodora Fetsi $^{1}$ \\ ${ }^{1}$ Land and Water Division, Food and Agriculture Organization (FAO) of the United Nations, Rome, Italy \\ Correspondence: Feras Ziadat, Food and Agriculture Organization (FAO) of the United Nations, Viale delle \\ Terme di Caracalla, Rome, 00153, Italy. Tel: 39-065-705-4079. E-mail: feras.ziadat@ fao.org
}

Received: November 24, 2020

Accepted: December 23, 2020 Online Published: January 16, 2021

doi:10.5539/sar.v10n1p73

URL: https://doi.org/10.5539/sar.v10n1p73

\begin{abstract}
This paper provides a brief overview of how traditional concepts and approaches of land use planning have evolved into a more widely accepted vision of 'land resources planning' and its requirements for participatory processes, involvement of multi-sectoral stakeholders, and multi-thematic information at appropriate scales. Given its comprehensive ambitions, land resource planning (LRP) has a growing demand for a wide-ranging toolset, encompassing different tools in the biophysical, socio-economic, and governance (in a form of guidelines, methods, approaches and support tools).

In order to collate knowledge, experiences and lessons from the LRP tools users, the Food and Agriculture Organization of the United Nations (FAO) - Land and Water Division held a consultation process through a survey among a range of stakeholders operating at different levels, sectors and regions. The survey evidenced limited awareness about the current availability of tools for land use planning. To remedy this situation, FAO developed the Land Resources Planning Toolbox (LRPT), a web-based inventory of existing tools.

The Toolbox makes distinguishing between the tools in the socio-economic domain, those in the biophysical and the ones combining the two domains. The Toolbox explains the ability and restrictions of the LRP tools and their appropriateness to different regions, stakeholders and levels, and can be searched according to several criteria.

It is concluded that, the Toolbox offers a useful mechanism for knowledge sharing and exchange of recent tools to enhance participatory LRP. It also has a great potential to support sustainable land management and landscape restoration. In this way it addresses, indirectly, conflicts and competition over resources.
\end{abstract}

Keywords: land resources evaluation, land use planning, sustainable land management

\section{Introduction}

\subsection{Defining Land Resources Planning}

As the world's population keeps increasing, the demands for land set aside for crops, grazing, forestry, nature conservation, industrial or urban development keep growing. In its guidelines for land use planning, the Food and Agriculture Organization of the United Nations (FAO) defined 'land use planning' as 'the systematic assessment of physical, social and economic factors in such a way as to assist land users with the selection of land use options that increase their productivity, are sustainable and meet the needs of society' (Food and Agriculture Organization of the United Nations [FAO], 1993). Hence, land use planning aims to make use of limited land (and water) resources, in a way that it yields optimal benefits for a given population and avoids conflicts over how and by whom the tracts of land are used.

Land use planning is a key tool to support sustainable land resources use and management, as indicated in the World Soil Charter (FAO, 1982; FAO, 2015), and the UN Conference on Environment and Development (United Nations, 1993) In the context of global population growth, increasing use/misuse of scarcer land resources, land degradation, biodiversity loss and climate change, proper planning of land resources use is becoming more critical than ever. Land use change has a significant impact on the ecosystem (Bizuhoraho et al., 2018).

In the past the term 'land use planning' was considered a synonym for 'central' planning. While efficient in terms of clarity about the chain of command, the approach had serious drawbacks. In many instances the effectiveness of land use planning was hindered by top-down approaches by governments and development agencies that 
failed to recognize the role of local communities in the planning process. This has led to different perceptions of problems between national or regional planners and communities, followed by failure to address all relevant issues and lack of cooperation in plan implementation by local communities (FAO, 1997).

Modern approaches to land-use planning recognize the principle of 'devolved' planning, whereby the primary land users, such as farmers, herders, etc., have a recognized stake in the planning processes, along with the actors who use the land for different purposes (settlements, forest use, source of energy, industry, mineral resources, recreation or tourism). Managing the interests of various stakeholders through formalized participatory negotiation processes has nowadays become a major element of land resource planning (Bourgoin et al., 2012; Bonnal, 2013; Tarrason et al., 2017).

Land resource planning (LRP), a more recent overarching term for land use planning, aims to add specificity to the nature of sound land use planning, by describing its requirements for participatory processes, involvement of multi-sectoral stakeholders, and needs for multi-thematic information at appropriate scales. LRP therefore covers a wide spectrum, which encompasses the land resources, land uses, users and planners, and the scales/levels of planning. Given its comprehensive ambitions, land resource planning is a highly complex subject.

\subsection{Basic Concepts and Principles of Land Resource Planning}

LRP is a process for selecting and putting into practice optimal sustainable land management (SLM) options within a given landscape. LRP involves a set of phased actions that use a number of time-tested approaches in accordance with some guiding principles.

The focus of LRP is on land, in all its elements: the characteristics of the land resource base, the use and users of land, as well as the tenure or ownership rights governing specific tracts of land (land units). In most cases the same land has potential for several uses, and decisions that lead to change in land use may lead to conflict between different categories of land users who use and manage the land differently. Examples of potential negative impacts include soil degradation, soil sealing, deterioration of water quality, loss of biological resources, damaging the ecosystem, salinization (Zdruli et al., 2016).

In order to ensure negative impacts of land use (change) are kept to a minimum, each LRP process involves several phases of activities, which can be pooled under the labels 'Assessment', 'Planning', 'Landscape Management', and 'Monitoring' (Figure 1). The assessment phase involves a proper characterization of the state and trends in the land and water resource base, with adequate attention to eventual degradation, conservation, or restoration features. The planning stage involves the actual implementation of an agreed land resources development plan. In order to ensure that the main stakeholders in current or planned land resource development agree to the proposed plan, it is essential that the land use planning process is guided by participatory approaches and negotiation procedures.

Once a plan for the integrated management of a landscape is approved, it is to be followed by a development phase in which specific project activities and SLM practices are implemented. Progress, results and impacts of plan implementation requires monitoring in order to inform decision-makers and make eventual interventions or plan adjustments.

As each planning situation is unique and cannot be covered by referring to textbooks, the entire LRP process is by nature iterative, with interlinked steps, and gives due recognition to the fact that good planning is essentially a collaborative learning process. In order to work, an enabling environment is essential, of which the main elements are (i) a strong institutional framework that can actually implement sustainable territorial development agendas, policies, plans and programmes, (ii) effective consensus-building approaches among stakeholder economic sectors and land users to address competing interests, and (iii) a spirit of collaboration formalized in goal-oriented partnerships between different actors (Khamzina et al., 2017). In order to avoid the trap of top-down planning, it is essential to adopt a multi-scale approach to planning, in which different kinds of planning and decision-making are entrusted to different administrative levels and actors, with flows of information in both directions (Figure 2). 


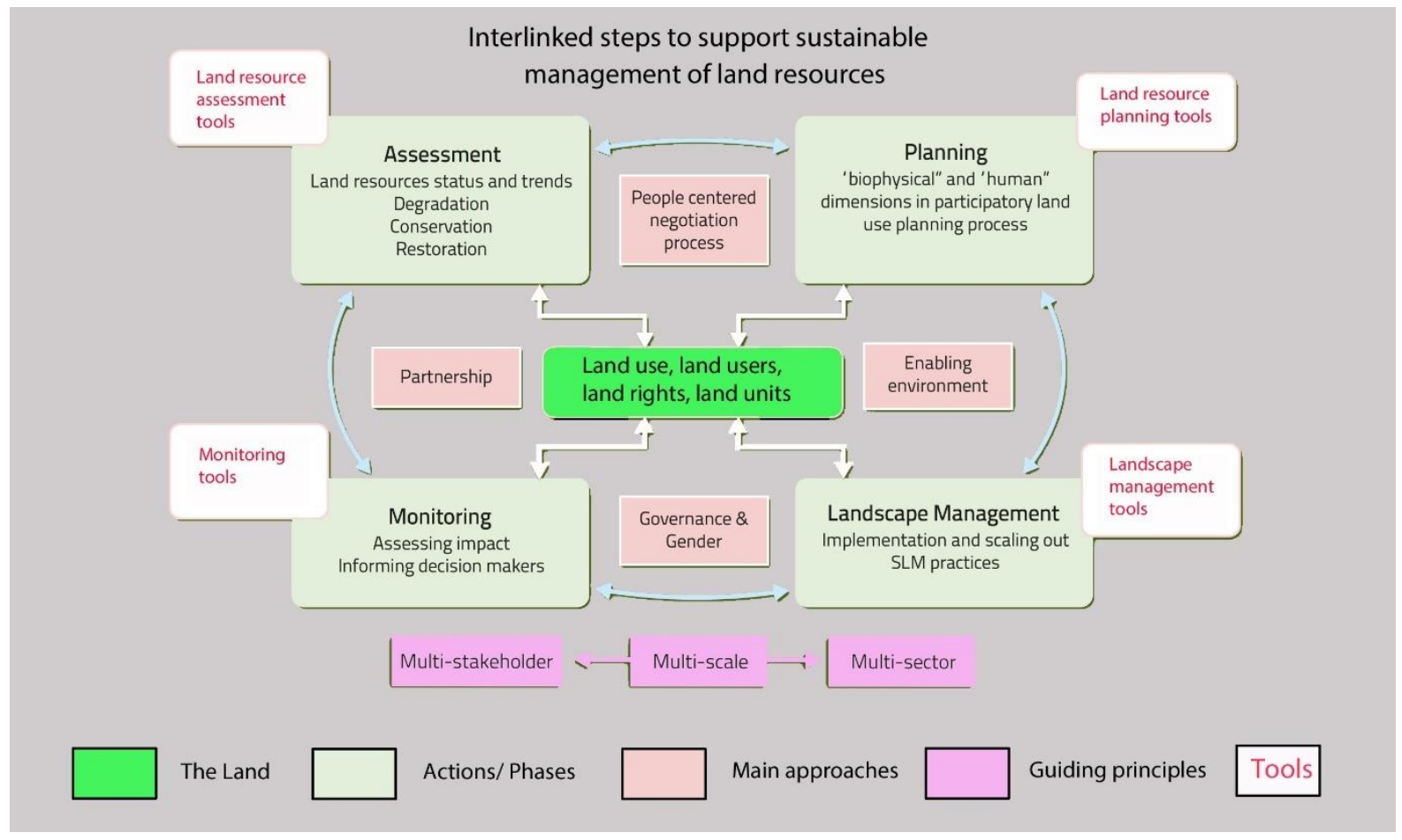

Figure 1. Interlinked actions/phases, approaches, guiding principles and tools involved in land resource planning

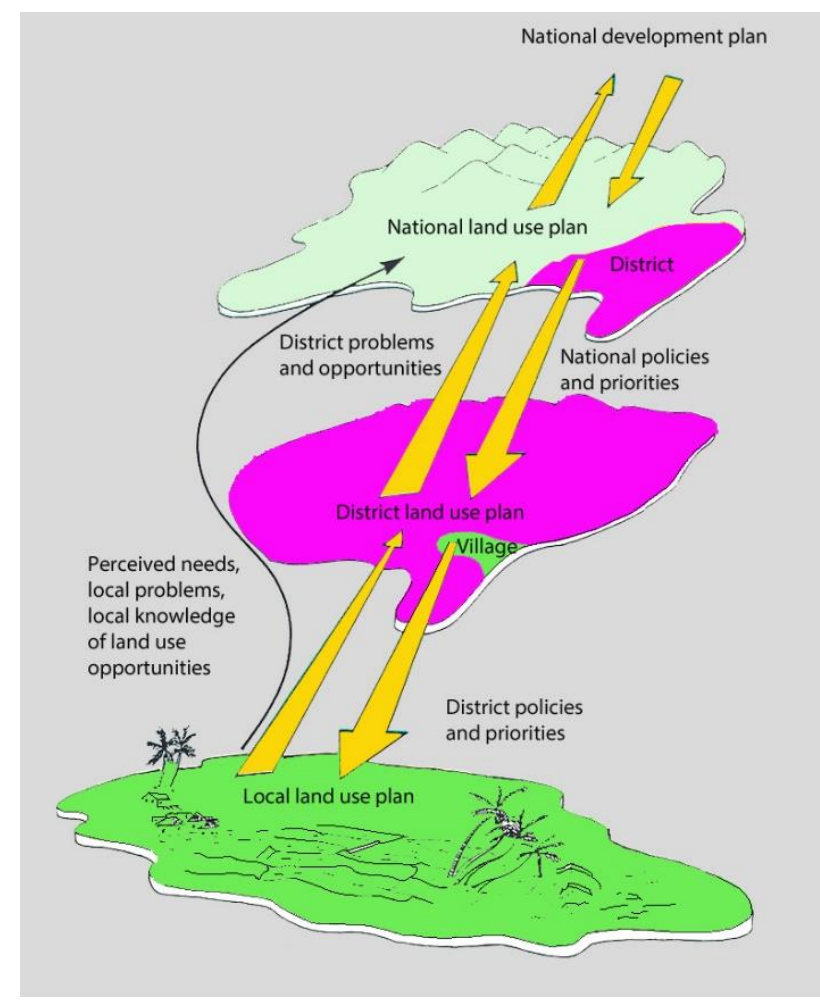

Figure 2. Linkages between different levels in multi-scale planning (source: FAO, 1993)

Given its complexity, LRP can be much assisted by appropriate tools that cover particular aspects and stages of the process. Of great value in this respect appear (i) statistical and geo-referenced databases on all land resources, on actual land use, functions of land and socio-economic conditions, (ii) spatial planning tools (e.g. GIS) to integrate the databases in a unified system that is able to incorporate temporal and spatial changes, (iii) 
interpretive tools to incorporate both biophysical and human dimensions (such as gender) into land use recommendations; (iv) multiple-goal analysis and optimization techniques of the harnessed data and (v) social, economic and political tools for decision-making on land use.

Knowledge and effective use of these tools requires expertise from different disciplines, which again stresses the need for partnership in land resource planning.

\subsection{The Emerging Need for a Land Resources Planning Toolbox (LRPT)}

LRP was developed from an early top-down to a more participatory planning approach taking into consideration the emerging biophysical and socio-economic challenges in order to ultimately provide decision-support means, all together labeled as "tools". The use of these tools supports and facilitates the decision-making processes from national to local level regarding the optimal use of natural resources leading to prevention of further degradation. However, with the current plethora of LRP tools, it would not be surprising if potential user categories were unaware of the whole range of tools available to address their needs.

In order to probe the tool awareness by actors involved in land resource planning, FAO's Land and Water Division implemented a global survey targeting a variety of stakeholders to collate knowledge and experiences on the use of LRP tools. The survey provided evidence that even within the land use/resource planning target group, let alone the public at large, limited awareness exists about the different tools, databases and support tools that are currently available for land use planning. To remedy this situation FAO developed the Land Resources Planning Toolbox (LRPT), a web-based inventory of existing tools and approaches in the form of a regularly updated toolbox in support of participatory land resources planning.

This paper examines in more depth these developments and is structured as follows:

- A review of methods, results and conclusions from the land resource planning survey;

- An explanation of the structure and major contents of the LRPT;

- Conclusions and recommendations in respect of further development of the toolbox to address user needs.

\section{Method}

\subsection{The Land Resource Planning Survey}

In order to answer questions about the use and relevance of land resource planning tools, FAO launched a multilingual survey in the six UN official languages, aiming at receiving the views of several stakeholders from different sectors on the matter. The specific goals of the survey entitled "Review and Evaluation of Participatory Land Use / Resource Planning Tools" were to collect information about the available tools, the typology of users (stakeholders), current challenges, demands and gaps, needs for knowledge sharing, and to agree on the next steps and actions to enhance knowledge and visibility of LRP tools.

SurveyMonkey was used to implement the survey. It contained single- and multiple-answer categorical questions, consisting of mutually exclusive categories, as well as open-ended questions, probing for responses in a free-style format (Ziadat, 2017). Categorical questions were subject to basic statistical analysis, performed by SurveyMonkey, from which graphs and tables were generated. Further processing of the SurveyMonkey results was done in Excel, (i) to add up responses from all six language groups, and (ii) to streamline the choice of charts in order to facilitate interpretation. Both single-answer and multiple-answer categorical questions were visualized using bar or column charts showing percentages of the respondents in each category.

The survey was initially tested in English by a core group of 35-members of FAO and external respondents, and at a second stage it was distributed globally through various networks. A total of 747 responses were received (454, 88, 79, 71, 51, 4 from English, Spanish, French, Russian, Arabic and Chinese-speaking respondents, respectively), belonging to a wide spectrum of organizations involved in land resources planning and covering a wide range of disciplines.

\section{Results}

\subsection{Main Findings}

The majority of survey participants had academic/research affiliations, whereas governmental, intergovernmental/international and non-governmental organizations were also well represented. On the other hand, participation of farmers and farmer organizations was low. The respondents' organizations and networks mainly offer support on policy, technical advice and education, capacity building and extension. Other important types of organizational support are backing for development projects and related activities. The survey participants cover a very wide range of disciplines, but about half of the respondents classify themselves as either technical specialists or scientific advisors. The dominant disciplines included land use/resources planning, 
soil conservation and water resources management, and ecosystem and environmental management. The majority of respondents operate in Africa, followed by Europe and Central Asia, and work mostly at national and sub-national level.

The use of many LRP tools to support the planning process was indicated by most of the respondents. Tools that provide decision support in the biophysical domain are the most frequently used, such as agro-ecological zoning, land evaluation (similarity and suitability), and land capability classification. For example, the availability of land and crop suitability for intercropping determine the land use pattern and the intercropping of various crops (Rikitu et al., 2019). Many respondents reported frequent use of databases, particularly on state and trends of the land resource base (soil types, degradation, conservation), climate, and agricultural statistics. The following are the only tools with socio-economic emphasis that are used by large number of the respondents: Rapid rural appraisal, negotiated territorial planning and participatory land use planning.

An interesting finding of the survey is that about $20 \%$ of the respondents use tools and databases that are not listed in the questionnaire, some of these were developed by the users. These cover a very diverse charge for decision support, including customized models to support land use decisions at local level, participatory land use planning, tools to support participatory process at local level, GIS-based tools, and different models and databases, satellite imagery and field survey data.

The majority of respondents, on average two out of three, explained that they are satisfied with the tools and databases they use. At the same time a large majority expressed the need for more or better tools for different land sectors, but particularly for agriculture, and even more pointed out the need for tools that address the issue of sectors integration. A substantive minority indicated that the available tools and databases did not meet their needs. The main issues around limited tool utility concerned availability and accuracy of input data, accessibility to the planning tools/ approaches, technical gaps of the tools, accuracy/ relevance of the outputs from the tools, effective implementation to support LRP decisions, operational considerations, and lack of capacity.

With respect to data for land use planning, the most common shortcomings mentioned were the quality of the data in terms of low resolution (both spatial and/or temporal), which leads to using information that is not appropriate for the level/scale of analysis.

The majority of respondents agreed that better decision support tools are necessary to support LRP, with better access to data/information that provide more practical utility. They see a need for new tools at all scales, with a slight preference for local-level (village/community) decision support tools, compared to those at national, sub-national, watershed or landscape levels. The demand is higher for tools in the socio-economic than in the biophysical domain, and the highest demand is for integrated biophysical and socio-economic tools.

Not all tool development requires digital platforms for use. The high demand for hard-copy documents about the tools was surprisingly highlighted in the survey responses.

\subsection{Regional Accents}

In most cases disaggregation of the categorical questions by region did not yield major differences between them. However, the open-ended questions did pick up mild distinctions of regional-specific perceptions of bottlenecks and gaps, challenges and which approaches and actions to follow for addressing these.

In Africa the main challenges are linked to (i) limited availability of land resources information, (ii) inadequate stakeholders and decision makers' awareness of the significance of land resource planning, (iii) availability and access to technology and computing facilities, (iv) physical distance in remote area where internet connection is limited reduces the engagement and interest of technical and extension workers.

The land use planning experience in Asia is largely similar to Africa, but with more weight on: (i) ensuring inclusive participation of the stakeholders in the planning exercise, (ii) managing multiple goals in planning processes, notably upgrading productivity of the agricultural systems, while (iii) ensuring ecosystem services are maintained and negative effects of climate change are mitigated, and (iv) improving the capacity to use and implement LRP tools. Since the land use planning process is more advanced and institutionalized in Asia, Asia faces the daunting task of integrating bottom-up and top-down land use planning procedures, especially to avoid that planning decisions taken at local level are at loggerheads with directives at national level.

In Latin America, although integrated landscape management approach is perceived as the only rational approach, the following difficulties were identified: (i) the highest inequality in land distribution in the world, and (ii) the lack of a policy and legal framework, particularly with regard to land rights of indigenous populations. 
Within these systematic constraints, Latin America tries to adapt new visions for native territorial planning, by enhancing income generation activities that depend on sustainable use of natural resources, conservation of biodiversity and climate change adaptation.

In Europe, integrated planning is more advanced, where all interested sectors are considered, with a welldefined planning prospect that is aligned with sustainable development. Development plans follow established procedures and are supported by well-functioning legal frameworks.

In Central Asia a kind of reverse process is ongoing, whereby the formerly centrally planned economies of the region are slowly converted into market economies. This transformation is accompanied by a generally high level of poverty, and dependence on agriculture and natural resources for livelihoods and national income remains high, within a difficult climatic and environmental context.

In the Near East and North Africa land use planning is seen as mostly a theoretical concept, rarely applied in practice as its principles are insufficiently recognized, and therefore not supported, by decision-makers. Despite this severe impediment respondents from the region reaffirmed the urgency of integrated and inclusive land use planning at national, sub-national and local levels and agreed on the need for guidelines.

\section{Discussion}

\subsection{General Approaches to Address Land Resource Planning Needs}

The survey was taken up by a high number of different disciplines, pointing to the fact that land resources planning involves and is of interest to many and varied fields including but not limited to soil and water resources assessment, agro-climatology, agronomy, forestry, rangeland development, environmental monitoring, socio-economics and development planning. In order to avoid compartmentalization of related activities, projects and programs it is required to gather together these different actors and sectors in the planning process. Actions at national and sub-nationals levels were found to deserve specific attention.

With regard to the characteristics of the stakeholders, the survey indicated that there was a significant difference between the very active and the less active stakeholder groups. This is a situation that could lead to potential conflicts of interest and calls for a more balanced involvement of all stakeholder groups in the land use consultation process, adopting a real participatory approach.

Survey participants indicated their need for more and better tools for land resource planning, primarily for tools that make integrated approaches more feasible. This points in the first place to bottom-up development of tools, including gender-sensitive ones that solve local situations. This would enhance the success rate of the negotiating process, rather than results and tools that rely on 'expert' criteria. To make potential users more familiar with the land use planning tools and available databases, capacity building in their use will often be required. One should not only rely on user-friendly computer tools but providing printed material is also an important component of the capacity building and knowledge sharing process.

The specific needs in Africa could be met in part by: (i) reducing the complexity of the assessment tools and the often high data requirements. In this way field work and associated costs could be diminished, (ii) the inclusion of national decision makers in sub-national and local participatory processes, (iii) the establishments of decentralized regional teams that receive adequate resources to carry out the planning process, and (iv) the development of a digital platform that gives the opportunity to virtually meet and exchange ideas with peers and other experts. The development of specific mobile phone applications that assist specific aspects of land resources planning.

The main challenge identified in Asia was to create ways and means to avoid top-down planning. To establish a mechanism that fosters the dialogue between stakeholders and decision makers at the different levels would be a necessary first step. Another issue is that given the level of development present in Asia, the focus should be on developing tools that allow to monitor indicators for markets responses to policy initiatives.

Land resource planning in Latin America identified the need for enhanced tools specifically aimed at local levels and community interventions. Capacity building in the region should support the adaptation of land resource planning tools at the right intervention level where they have the most impact. At the same time a platform could be created that fostered the exchange of information and the collaboration of national experts at all levels.

In Central Asia more information is needed at country level about the way the actual land resource planning is undertaken. Generally, there is a recognized need to move away from the centrally planned top-down coordination of land use planning towards a more participatory and decentralized way of planning the use of land resources. 
A conclusion applicable to all regions is that there is no single land resource planning guideline that caters for all situations at all levels. Instead, one could focus on planning for key conditions that are representative for the production systems and the biophysical and socio-economic conditions in the region. Climate change projections should also be taken into consideration. Due attention should be paid to strengthen the participatory aspects of the planning projects. All available relevant tools and databases should be considered and their use included in the training part of the capacity building process. Both user-friendly computer tools and paper material will be required.

\subsection{Development of a Land Resources Planning Toolbox}

The LRP survey described above provided evidence for the increasingly complex environments in which decision- makers and advisors at different levels have to operate in order to fulfill the demands of modern land resource planning for interdisciplinary problem diagnosis, multi-stakeholder negotiation, multi-actor partnership building, and enabling institutions and policies. Many of the respondents indicated that they used local tools that did not feature in the preliminary survey, while some respondents were not familiar with the tools, databases and approaches that are relatively widely used for LRP. In order to take into account these findings, FAO inventoried a whole range of existing LRP tools and approaches. This inventory became the basis for the development of the Land Resources Planning Toolbox (LRPT).

LRPT is a freely accessible online resource for a range of stakeholders, directly or indirectly involved in land use planning (planners, policy makers, governments, institutions, communities, technical specialists, etc.). The overall goal of the Toolbox is to make potential users aware of the existence of these tools, facilitate access to their information, and assist with the selection of those tools that meet the requirements of different stakeholders, operating at different levels, regions, and sectors. The Toolbox offers a useful platform to exchange results and share experiences with the use of state-of-the-art LRP tools and approaches. The Toolbox promotes participatory approaches and has a significant potential to support integrated landscape management and land restoration processes. In this way it addresses indirectly conflicts and competition over land resources. At the time of writing, LRPT contained 157 tools.

To achieve these objectives and maintain LRPT up-to-date, new tools, when identified or developed by users, are to be incorporated in the database and in this way enhance the visibility of the developers as well as assist other users in exploring and using tools that may help to achieve their land use plans. To guide the development of new tools for land resources planning, more attention needs to be paid to constraints and opportunities over a range of scales and across sectors involving all stakeholders. Ideally field projects could be designed and implemented to validate and fine-tune existing and new tools for their capacity to meet land use targets from the national to the local level.

\subsection{Toolbox Structure and Content}

The Toolbox contains summary descriptions and links for a comprehensive number of land resource planning tools and approaches developed by FAO and other institutions. The overall structure and content of the LRPT is presented in Figure 3. The tools featured are grouped into five main categories that encompass different thematic domains in the land use planning process. These categories are: (i) biophysical approaches/ tools, (ii) socio-economic and negotiation approaches/tools, (iii) integrated biophysical, socio-economic and negotiation approaches/tools, (iv) databases/information systems, and (v) support tools.

Biophysical approaches/tools give prominence to the characterization of biophysical attributes (climate, soil, terrain, water, etc.) and to methods that guide users towards suitable options for land use alternatives, based mainly on these attributes. Land suitability and similarity analysis are typical examples. LRPT includes documents describing principles, approaches and guidelines for land evaluation, as well as different tools for classifying soils based on the potential for a specific use, or constraints for fertility and management. It includes models of crop growth and yield predictions. Representative examples are FCC (Sanchez et al., 1981), FLE (FAO, 1976), GAEZ (FAO and IIASA, 2012), LCC (Helms, 1992), SWAT (Neitsch et al., 2011) (Note 1). LRPT contains 35 tools in this category.

Socio-economic and negotiation approaches/tools cover aspects of the human environment (farming systems, tenure, gender, participatory planning etc.). The 14 tools in this category give prominence to the characterization of social and economic settings required for land use planning and includes approaches and methods of participatory decision-making. Biophysical conditions may be considered in these tools, but not in depth. Characteristic examples are COMAP (WaterAid, 2005), IGETI (FAO, 2012a), ELMO (Emerton, 2015), PNTD (FAO, 2005) and VGGT (FAO, 2012b). 
Integrated biophysical, socio-economic and negotiation approaches/tools make joint use of methods applied in both biophysical and socio-economic spheres and process information on both biophysical characteristics and social and economic conditions. They generally incorporate principles, approaches and methods of participatory land use planning, with the overall objective of reaching mutually beneficial outcomes for all stakeholders. Typical examples are DPSIR (Kristensen, 2004), FESLM (Smyth, 1993), Guide_LUP (FAO, 1993), LADA_LOC (Nachtergaele, 2016), and RRA (Crawford, 1997). LRPT contains 31 integrated tools.

The category "Databases/ Information systems" includes tools that can facilitate land evaluation and land use planning by providing input data and information. The 45 databases in LRPT generally encompass maps and data on soil and terrain characteristics, land degradation, land cover, land use, climatic data including future projections, crops and yields, food, agriculture, water resources, adaptability/suitability of identified plant species for a given environment, and socio-economic data and statistics on poverty, population, tenure and gender. Some typical examples are AFSIS, AQUASTAT, WOCAT, WORLDCLIM, and WORLDPOP.

The support tools do not produce results that have direct use for land evaluation and land use planning but have a supporting role by providing various types of information that can be used in land evaluation studies and as input data sets for land use planning. Representative examples of the 32 tools in LRPT are COOLFARM, EX-ACT, HORTIVAR, QGIS, and SEEA.

Each main category is subdivided into sub-categories, according to the similarity in information content (Figure 3 ). Characteristic for the sub-categories is that they belong exclusively to one main category, but not to another. The tools are further characterized in terms of thematic area, type of tool, scale of applicability and user category.

The "Thematic areas" class categorizes the tools according to their main focus. Since most of the tools are often covering more than one theme and are multi-disciplinary in nature, users can identify more than one thematic area to search for appropriate tool(s). The "Type of tool" class categorizes the tools according to the nature of the published material that the users can access and use. Some tools are published in different formats and the users could be interested in certain formats of tools for the application at hand.

The "Scale of applicability" classification shows the different spatial scales under which the tool is expected to be most useful and relevant. This is based on the nature of the tool and, in some cases, on the original scale under which the tool was developed. The "User category" defines the target group for which each tool is suitable.

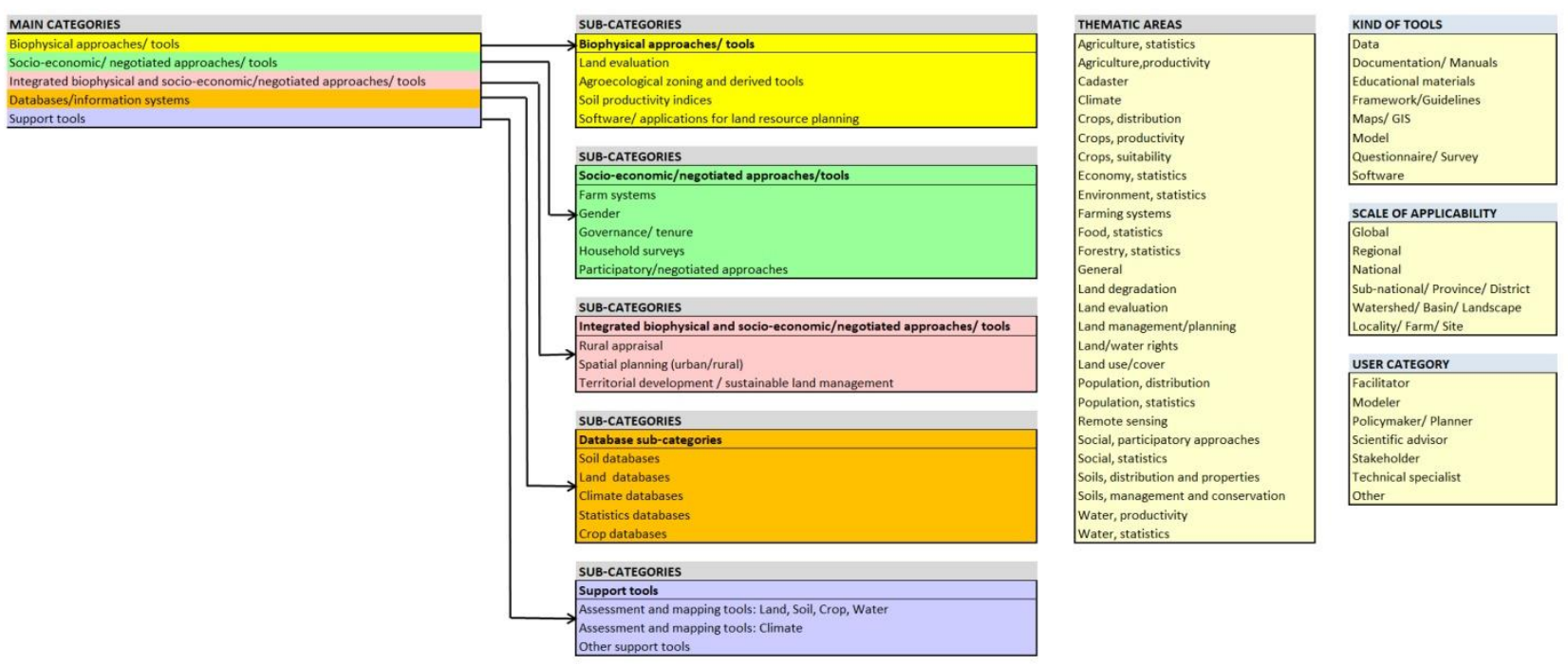

Figure 3. Search criteria and options for the Land Resources Planning Toolbox

\section{Acknowledgment}

The authors would like to acknowledge the contribution of Sally Bunning, Paolo Groppo, Riccardo Biancalani, Sergio Zelaya-Bonilla, Rosalud de la Rosa, Thomas Hammond, Stefan Schlingloff, James Morgan, Alastair Sarre and Stephan Mantel (ISRIC) for their support in implementing the LRP survey, editing and layout of the LRP toolbox. 


\section{References}

Bizuhoraho, T., Kayiranga, A., Manirakiza, N., \& Mourad, K. (2018). The Effect of Land Use Systems on Soil Properties; A case study from Rwanda. Sustainable Agriculture Research, 7(2), 30-40. https://doi.org/10.5539/sar.v7n2p30

Bonnal, J. (2013). Negotiating land and water use: participatory planning of resource management. FAO Land and Water Division Working Paper 6. Retrieved from http://www.fao.org/3/mi371e/mi371e.pdf

Bourgoin, J., Castella, J., Pullar, D., Lestrelin, G., \& Bouahom, B. (2012). Toward a Land Zoning Negotiation Support Platform: "Tips and tricks" for Participatory Land Use Planning in Laos. Landscape and Urban Planning, 104, 270-278. https://doi.org/10.1016/j.landurbplan.2011.11.008

Crawford, I. M. (1997). Marketing research and information systems. Chapter 8: Rapid rural appraisal. FAO Regional Office for Africa. Retrieved from http://www.fao.org/3/w3241e/w3241e00.htm\#Contents

Emerton, L., Snyder, K., \& Cordingley, J. (2015). Evaluating Land Management Options (ELMO): a participatory tool for assessing farmers' sustainable land management decision preferences and trade-offs. Nairobi, Kenya: International Center for Tropical Agriculture (CIAT). p. 18. Retrieved from https://core.ac.uk/download/pdf/132679139.pdf

FAO. (1976). A framework for land evaluation. FAO Soils bulletin 32. Retrieved from http://www.fao.org/3/x5310e/x5310e00.htm

FAO. (1982). World Soil Charter. Environmental Policy and Law, Volume 8, Issue 2, 1982, Pages 62-64. Food and Agriculture Organization of the United Nations. https://doi.org/10.1016/S0378-777X(82)80103-0

FAO. (1993). Guidelines for land use planning. FAO Development Series 1. Rome.: Food and Agriculture Organization of the United Nations. p. 96. Retrieved from http://www.fao.org/3/t0715e/t0715e00.htm

FAO. (1997). Negotiating a sustainable future for our land - Structural and institutional guidelines for land resource management in the 21st Century. Rome: Food and Agriculture Organization of the United Nations. p. 96. Retrieved from http://www.fao.org/3/a-bo779e.pdf

FAO. (2005). An approach to rural development: participatory and Negotiated Territorial Development (PNTD). Rural Development Division. Food and Agriculture Organization of the United Nations. Retrieved from http://www.fao.org/3/a-ak228e.pdf

FAO. (2012a). Improving Gender Equality in Territorial Issues (IGETI). Land and Water Division Working Paper 3. Food and Agriculture Organization of the United Nations. Retrieved from

Retrieved from http://www.fao.org/3/me282e/me282e.pdf

FAO. (2012b). Voluntary guidelines on the responsible governance of tenure of land, fisheries and forests in the context of national food security. Rome, Italy: Food and Agriculture Organization of the United Nations. Retrieved from http://www.fao.org/3/a-i2801e.pdf

FAO. (2015). Revised World Soil Charter. Rome, Italy: Food and Agriculture Organization of the United Nations. Retrieved from http://www.fao.org/3/a-i4965e.pdf

FAO and IIASA. (2012). GAEZ (v3.0) Global Agro-Ecological Zones User's Guide. Retrieved from http://www.fao.org/nr/gaez

Helms, D. (1992). Readings in the history of the soil conservation service. Washington, DC: Soil Conservation Service. p. 60-73. Retrieved from https://www.nrcs.usda.gov/Internet/FSE_DOCUMENTS/stelprdb1043484.pdf

Khamzina, A., Börner, L., Cofie, O., Drechsel, P., Gordon, C., Miranda, J., ... Ziadat, F. (2017). Land resources and the SDGS. In: land degradation and the Sustainable Development Goals: Threats and potential remedies. CIAT, 2017. Retrieved from https://www.researchgate.net/publication/317600848_Land_resources_and_the_SDGs

Kristensen, P. (2004). The DPSIR framework. National Environmental Research Institute, Denmark Department of Policy Analysis, European Topic Centre on Water, European Environment Agency. Retrieved from https://wwz.ifremer.fr/dce/content/download/69291/913220/.../DPSIR.pdf

Nachtergaele, F., Biancalani, R., Bunning, S., McDonagh, J., Rioux, J., \& Woodfine, A. (2016). Land Degradation Assessment in Drylands (LADA). Manual for local level assessment of land degradation and sustainable land management, Part 1: Planning and methodological approach, analysis and reporting. FAO, 
Rome, Italy. Retrieved from http://www.fao.org/3/a-i6361e.pdf

Neitsch, S. L., Arnold, J. G., Kiniry, J. R., \& Williams, J. R. (2011). Soil and water assessment tool. Theoretical Documentation. Texas Water Resources Institute Technical Report No. 406. Retrieved from https://swat.tamu.edu/media/99192/swat2009-theory.pdf

Rikitu, A., Emana, B., Haji, J., \& Bekele, K. (2019). Smallholder Farmers' Decision to Participate in Vegetable Marketing and the Volume of Sales in West Shewa Zone of Oromia National Regional State, Ethiopia. Sustainable Agriculture Research, 8(4), 48-60. https://doi.org/10.5539/sar.v8n4p48

Sanchez, P., Couto, W., \& Buol, S. (1982). The fertility capability soil classification system: Interpretation, Applicability and Modification. Geoderma, 27(4), 283-309. https://doi.org/10.1016/0016-7061(82)90019-2

Smyth, A., Dumanski, J., Spendjian, G., Swift, M., \& Thornton, P. (1993). FESLM: An international framework for evaluating sustainable land management. FAO World Soil Resources Report. Retrieved from http://www.fao.org/3/t1079e/t1079e00.htm

Tarrason, D., Andrian, G., \& Groppo, P. (2017). Toolkit for the application of Green Negotiated Territorial Development (GreeNTD). FAO Land and Water Division Working Paper 16b. Retrieved from http://www.fao.org/3/a-i6591e.pdf

United Nations. (1993). Report of the United Nations Conference on Environment and Development. Rio de Janeiro, 3-14 June 1992. Volume I: Resolutions Adopted by the Conference. Retrieved from https://www.un.org/esa/dsd/agenda21/Agenda\%2021.pdf

WaterAid. (2005). Community mapping. A tool for community organizing. London, United Kingdom: WaterAid. Retrieved from https://washmatters.wateraid.org/publications/community-mapping-a-tool-for-community-organising-2005

Zdruli, P., Ziadat, F., Nerilli, E., D’Agostino, D., Lahmer, F., \& Bunning, S. (2016). Sustainable development of land resources. In zero waste in the Mediterranean. Chapter 4. Paris, France: Presses de Sciences Po. Retrieved from http://www.fao.org/3/a-bq976e.pdf

Ziadat, F., Bunning, S., \& De Pauw, E. (2017). Land resource planning for sustainable land management. FAO, Rome, Italy. p. 55. Retrieved from http://www.fao.org/3/a-i5937e.pdf

\section{Notes}

Note 1. Specific tools are identified in the paper by their acronym used in the LRP Toolbox. To obtain details on the tool, follow the link to the tool's entry in the Toolbox

(http://www.fao.org/land-water/land/land-governance/land-resources-planning-toolbox/en/).

\section{Copyrights}

Copyright for this article is retained by the author(s), with first publication rights granted to the journal.

This is an open-access article distributed under the terms and conditions of the Creative Commons Attribution license (http://creativecommons.org/licenses/by/3.0/). 